\title{
Study on the Impact of Varying Degrees of Underground Accidental Explosions on Underground Pipes by Simulation
}

\author{
Akinola Johnson Olarewaju ${ }^{1}$ \\ ${ }^{1}$ Civil Engineering Department, School of Engineering, Federal Polytechnic, Ilaro, Ogun State, Nigeria \\ Correspondence: Akinola Johnson Olarewaju, Civil Engineering Department, School of Engineering, Federal \\ Polytechnic, Ilaro, P.M.B. 50, Ilaro, Ogun State, Nigeria. Tel: 234-803-244-6036. E-mail: \\ akinolajolarewaju@yahoo.com
}

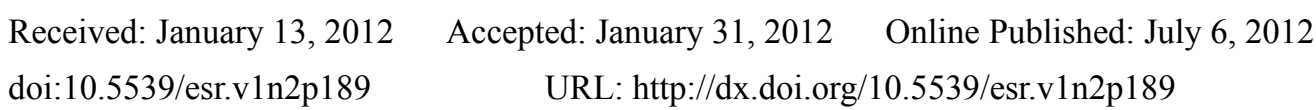

The research is financed by Ministry of Science, Technology and Innovation (MOSTI) Malaysia e-science grant No. 03-01-10-SF0042 at SKTM, Universiti Malaysia Sabah, 88999 Kota Kinabalu, Sabah, Malaysia (Tel: 60-102-453-947 \& 60-148-728-131).

\begin{abstract}
Underground accidental explosions are caused by the detonation of explosive materials (solid, liquid or gas) stored below the ground surface. In this study, response of underground pipes due to varying degrees of underground accidental explosions was studied using ABAQUS code. Pipes buried in loose sand, dense sand and undrained clay at $1 \mathrm{~m}$ depth below the ground surface were modelled. The material properties as revealed by several researchers were used. Pipe and soil materials were limited to linear, elastic, homogeneous and isotropic. The observed parameters are displacement, pressure, stress and strain at the crown, invert and spring-line of underground pipes. The results showed that irrespective of the ground media, displacement increases linearly as the loading wave velocity increases. Even though there is wide variation in the results due to dilations and compressions caused by the transient stress pulse of compression wave, observed parameters increases as the loading wave velocity increases.
\end{abstract}

Keywords: underground accidental explosion, pipes, structures, response, loading wave velocity, observed parameters

\section{Introduction}

Underground accidental explosion normally occur when an explosive material (solid, liquid or gas) explodes below the ground surface. Underground explosion can take place, broadly speaking, in sand as well as undrained clay with varying degrees of impact on underground structures. Depending on the mass and depth of burial of explosive charge as well as the geotechnical property of the ground medium, the consequence of underground accidental explosion is tremors which could be felt tens and hundreds of kilometres away from the point of burst of the buried explosive materials (Eric \& Shino, 2011). The load emanating from the blast wave is termed loading wave velocity. It denotes the blast load which the buried explosive charge delivered to the buried structures. The underground accidental explosion loads in terms of loading wave velocity reduce to seismic velocity of soil at less than $10 \mathrm{~m}$ from the source for explosive range of $10 \mathrm{~kg}$ TNT to $250 \mathrm{~kg}$ TNT buried in soils and undrained clay (Olarewaju et al., 2010b; 2010d; 2010h). Seismic velocity is a term describing the rate of propagation of an elastic wave through the earth due to disturbance in the earth caused by explosion or earthquake and it depends on the density and elasticity of the ground medium (Robert, 2002).

Due to complexity in accurately determining the mass of the explosive materials (i.e., solid, liquid and gas) that will produce the explosive loads on underground structures, there is need to study the consequences of these complexity. This is with a view to determining the extent and magnitude of the responses of underground structures like pipes due to varying degrees and impact of underground accidental explosions. Underground structures are divided into fully buried structures partially buried structures which can be any structure of diverse shapes such as, shelters, basement structures, underground mall facilities, underground parking spaces, silos, storage facilities, retention basins, shafts, tunnels, pipes, underground railway, metro stations, to mention a few. 
Pipes are underground installations which are used to convey petroleum products, sewage, industrial and domestic wastes, liquid gas, acid, gas in petrol-chemical industries, atomic reactor, means of transportation in underground, means of access in mining industries, storage facilities, piling for jetties berths and foundations, caissons, surface and underground main lines for irrigation and drainage, penstocks for hydro-electric projects, etc. Due to huge investment involved in the construction of underground pipes and tremendous usage across the world, there is need to study the responses of underground installations (like pipes) due to underground accidental explosions. This is with view to providing design information and guidelines for underground pipes to resist the effects of underground accidental explosions. Explosion-load-evaluation of underground structures at low depth of burial is important in designing explosion-resistant underground structures like pipes. This study is aimed at determining by simulation, the impact of varying degrees underground accidental explosions on underground pipes.

\section{Background Study}

Explosive materials (solid, liquid or gas), are stored above the ground surface, on the ground surface and below the ground surface depending on the volatility and proximity to the surrounding settlement. This is mostly carried out at: military formations where defensive weapons like war heads, bombs, grenades, etc are stored; filling stations where fuels and other crude oil derivatives are stored; manufacturing industrial sites where propane are stored underground; etc. Explosion loads could be evaluated using empirical, semi-empirical and numerical techniques as the case may be (Unified Facilities Criteria, 2008; Peter \& Andrew, 2009; Olarewaju et al., 2010a; 2010b; 2010d; 2011a; 2012). According to Unified Facilities Criteria (2008), explosive materials for underground explosions, confined and unconfined for surface explosions are expressed in kilogram $(\mathrm{kg})$ trinitrotoluene (TNT) equivalent for an explosive. This is the mass of TNT that would give the same blast performance as the mass of the explosive in question.

Soil-pipe interaction due to short discontinuous events like underground accidental explosions depends mainly on stiffness of the constituents rather than strength (Liang-Chaun, 1978; Olarewaju et al., 2010c; 2010g). Underground explosions (nuclear or otherwise) could be carried out for different purposes such as earthmoving mechanisms and crater formation, even though it may have spiral effects. When explosive material (i. e. nuclear weapon, bombs, etc) explodes under the ground, a sphere of extremely hot, high-pressure gases, including vaporized weapon residues, soil and rock, is formed. This is the equivalent of the fireball in an air or surface burst. The rapid expansion of the gas bubble initiates a ground shock wave which travels in all directions within the ground medium away from the burst point. When the upwardly directed shock (mainly compression) wave reaches the earth's surface, it is reflected back as a rarefaction (or tension) wave. If the tension exceeds the tensile strength of the surface material, the upper layers of the ground will split off into more-or-less horizontal layers (The Effects of Nuclear Weapons, 1977).

A plowshare program test was conducted on the $6^{\text {th }}$ July 1962 at the Nevada test site for the promotion of underground nuclear explosion to develop peaceful usage for the atomic energy. In this test, explosive of $104 \times 10^{3}$ tons displaced $12 \times 10^{6}$ tons of soil and released seismic energy of 4.75 Richter scale equivalents (United States Department of Energy, 2000; AubreyJ.org, 2006 - in public domain). The impacts of underground accidental explosions are mostly felt at grater distance from the source of the explosion (Robert, 2002; Eric \& Shino, 2011). The United States of America has conducted a lot of deep underground tests, especially since September 1961 according to The Effects of Nuclear Weapon (1977).

\section{Methodology}

In this study, $1 \mathrm{~m}$ diameter pipes buried in loose sand, dense sand and undrained clay at $1 \mathrm{~m}$ depth below the ground surface were modelled using ABAQUS software (finite element numerical code). According to Olarewaju et al. (2012), it is more necessary to evaluate the explosion resistance of underground structures at lower depth of burial. This is because the inter-atomic bonds of the material yield more at lower depth of burial than those buried at grater depth. The contact between the soil and pipe was defined for 'no slip' condition. Therefore it is assumed that perfect bond exist between the soil and the pipe. The soil and pipe materials were assumed to be linear, homogeneous and isotropic. As a result, the material properties as revealed by various researchers and pipe manufacturers were used (Craig, 1994; Kameswara, 1998). In line with Geotechnical Modelling and Analysis with ABAQUS (2009), boundary conditions were defined with respect to global Cartesian axis.

In line with ABAQUS Analysis Users' Manual (2009) and ABAQUS/Explicit: Advanced Topic (2009), analysis were carried out on simulated models by solving the governing equation of motion of the system shown in 
Equation 1 (with the initial conditions) using the time integration technique of the finite different scheme in ABAQUS/Explicit (Olarewaju et al., 2010c; 2010h; 2011c).

$$
[m][\ddot{U}]+[c][\dot{U}]+[k][U]=[P]
$$

where $m, c^{\prime}, k, U$ and $P$ are the global mass matrix, global damping matrix, global stiffness matrix, displacement and load vectors respectively while dot indicate their time derivatives (Kameswara, 1998; ABAQUS Analysis User's Manual, 2009; ABAQUS/Explicit: Advanced Topic, 2009).

The observed parameters are displacement, pressure, stress and strain at the crown, invert and spring-line of pipes buried in loose sand, dense sand and undrained clay as shown in Figure 1 (Olarewaju et al., 2010a; 2010g; 2011c). Underground accidental explosions were assumed to have taken place outside the vicinity of the buried pipes and as a result, explosion loads for explosives range of 10kg TNT and 250kg TNT were represented by the loading wave velocities for sand and undrained clay as shown in Figures 2 and 3 respectively.

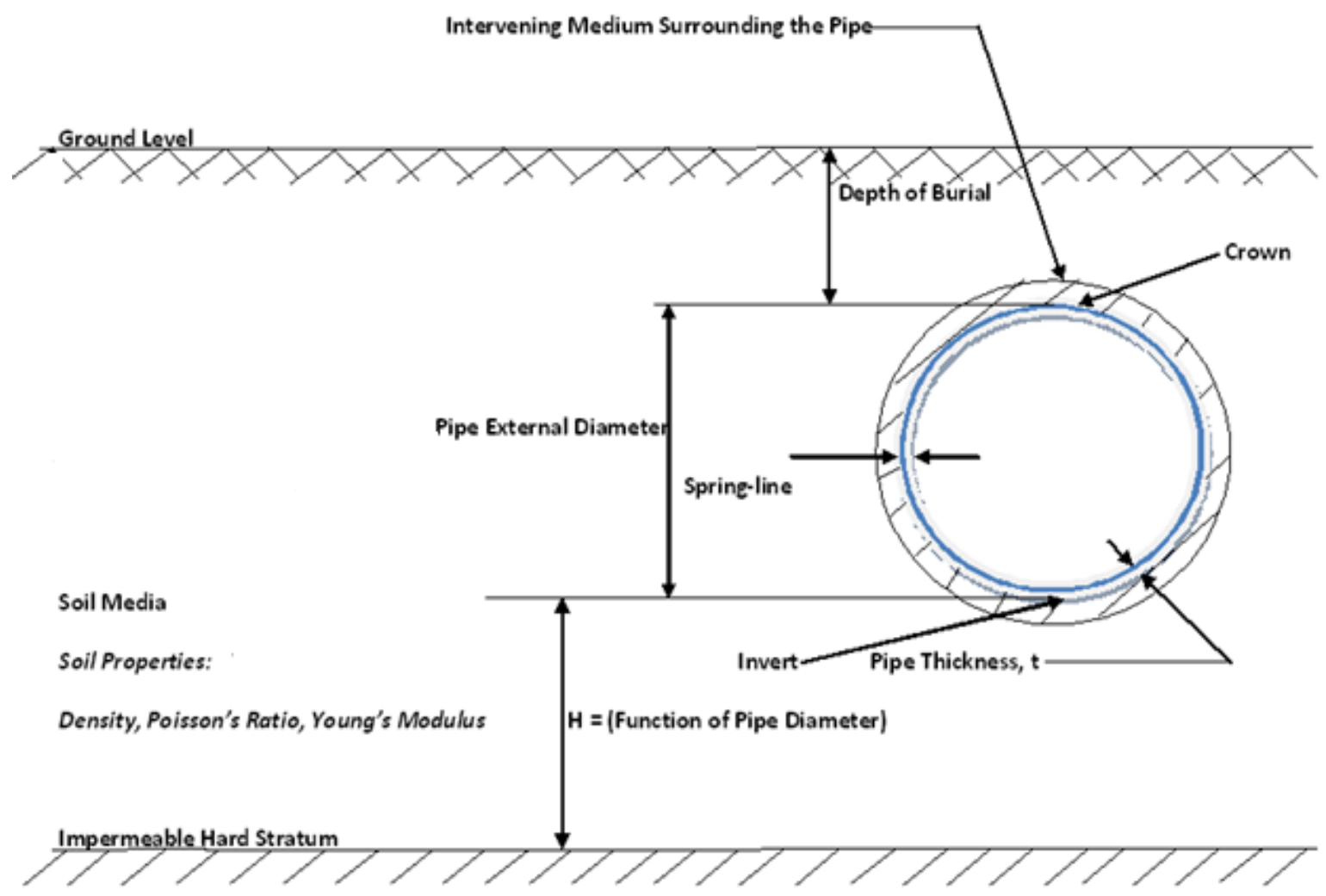

Figure 1. Problem definition for the response of underground pipe due to varying degree of impact of underground accidental explosions (Olarewaju et al., 2010a; 2010g; 2011c) 


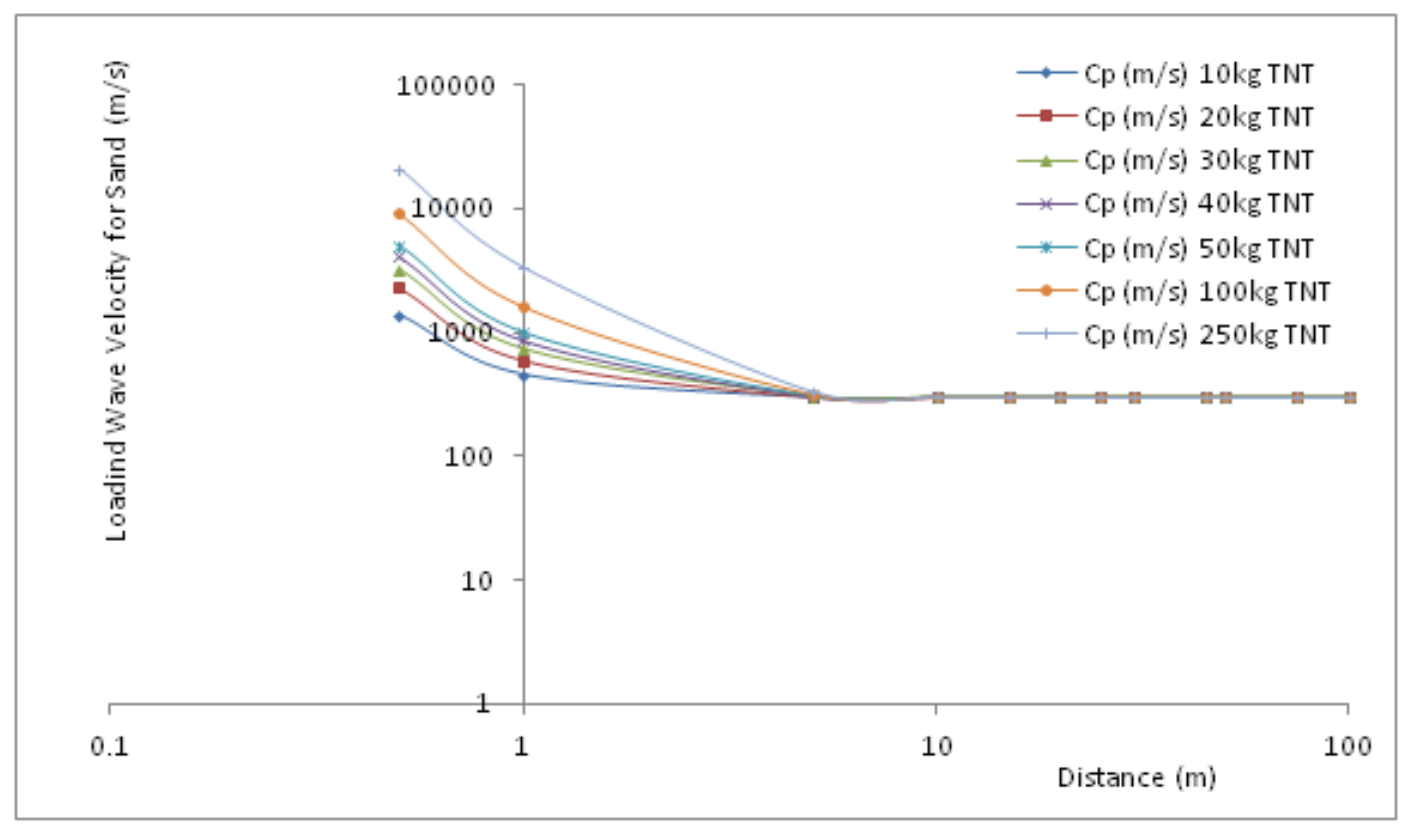

Figure 2. Loading wave velocity for sand at stand-off distance for varying weight of explosives (Olarewaju et al., 2010d; 2010e; 2010f; 2010h; Olarewaju et al., 2012)

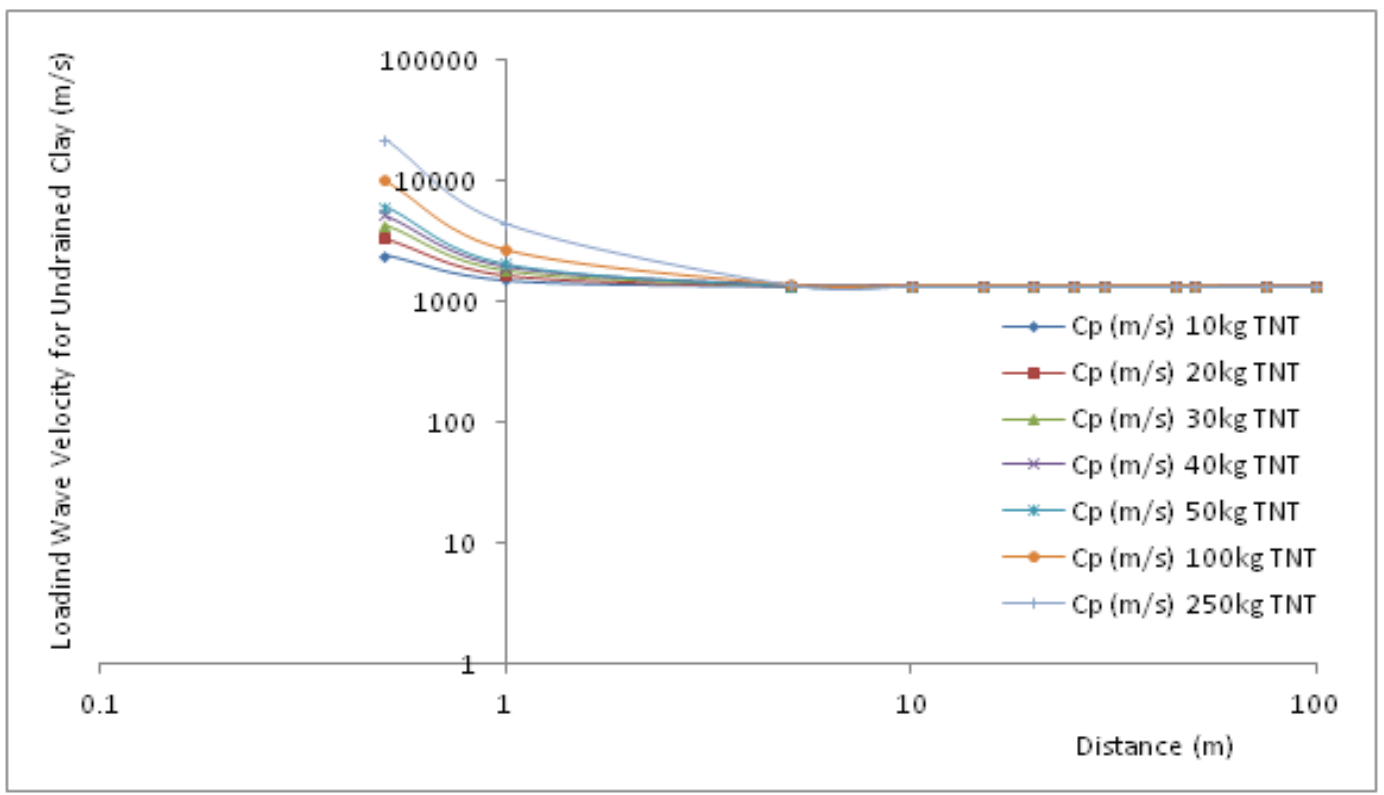

Figure 3. Loading wave velocity for undrained clay at stand-off distance for varying weight of explosives (Olarewaju et al., 2010d; 2010e; 2010f; 2010h; Olarewaju et al., 2012)

\section{Results and Discussion}

The results of loading wave velocities for explosives ranging from 10kg TNT to $250 \mathrm{~kg}$ TNT in sand and undrained clay due to underground accidental explosions, as obtained from Olarewaju et al. (2010d, 2010e; 2010f; 2010h) and Olarewaju et al. (2012) are presented in Figures 2 and 3 respectively. In addition to this, due to underground accidental explosions, the result of displacement at the crown, invert and spring-lie of pipes buried in loose sand, dense sand and undrained clay are presented in Figures 4, 5 and 6 respectively. Furthermore, due to underground accidental explosions, the result of pressure at the crown, invert and spring-line of pipes 
buried in loose sand, dense sand and undrained clay are presented in Figures 7, 8 and 9 respectively. Due to underground accidental explosions, the result of stress at the crown, invert and spring-line of pipes buried in loose sand, dense sand and undrained clay are presented in Figures 10,11 and 12 respectively. Finally, due to underground accidental explosions, the result of strain at the crown, invert and spring-line of pipes buried in loose sand, dense sand and undrained clay are presented in Figures 13, 14 and 15 respectively.

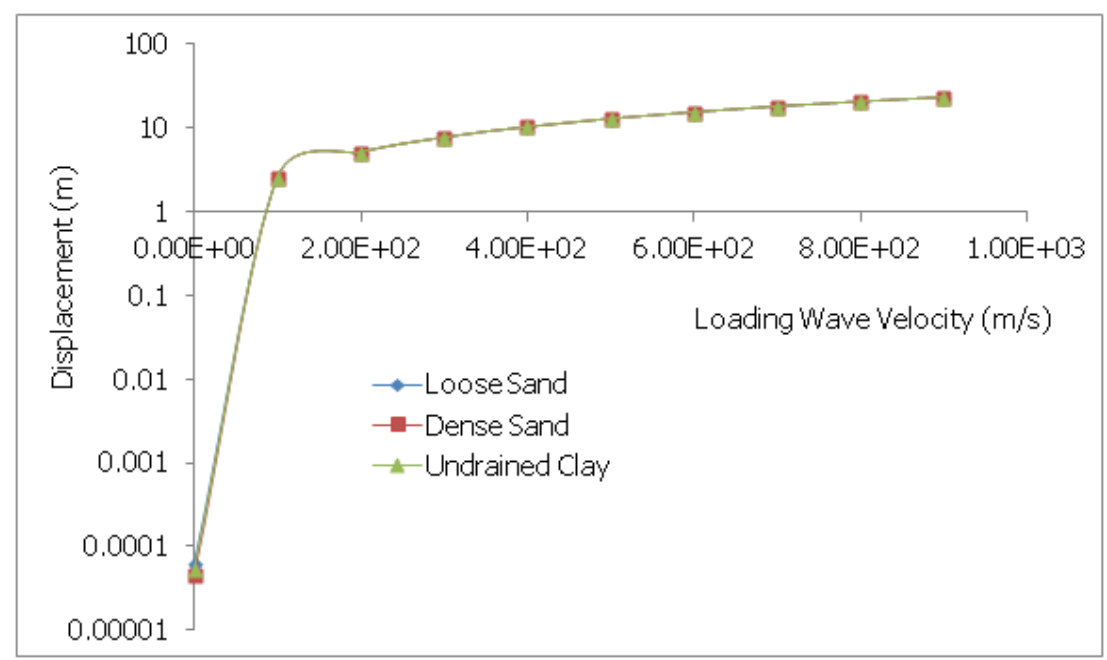

Figure 4. Displacement at the crown of underground pipes due to varying underground accidental explosions

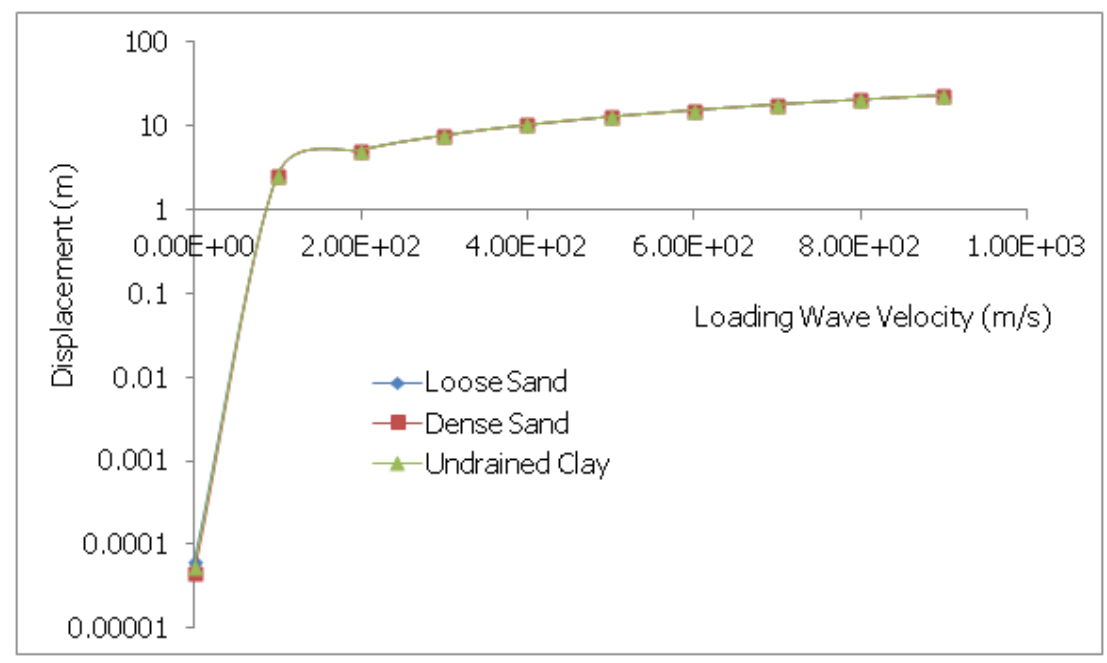

Figure 5. Displacement at the invert of underground pipes due to varying underground accidental explosions 


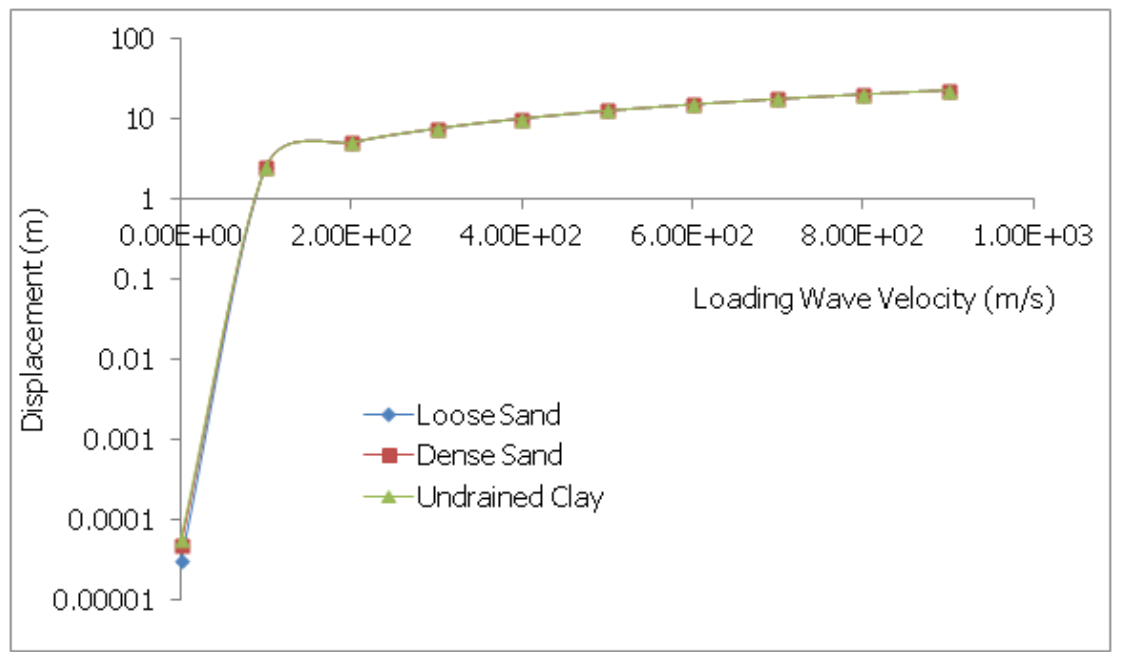

Figure 6. Displacement at the spring-line of underground pipes due to varying underground accidental explosions

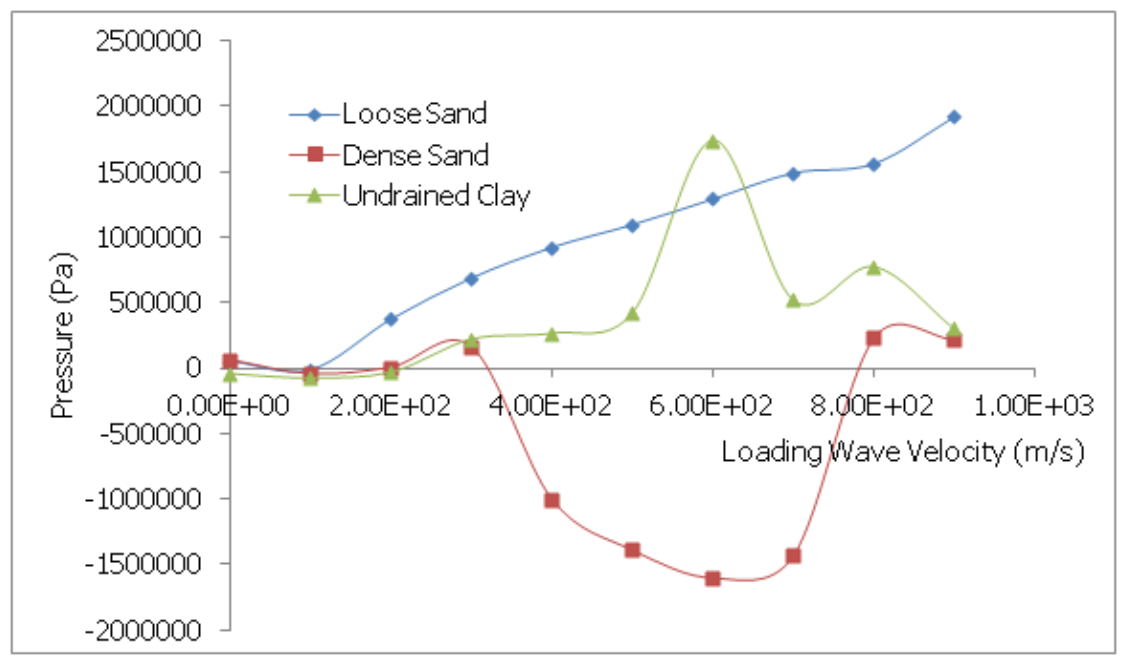

Figure 7. Pressure at the crown of underground pipes due to varying underground accidental explosions

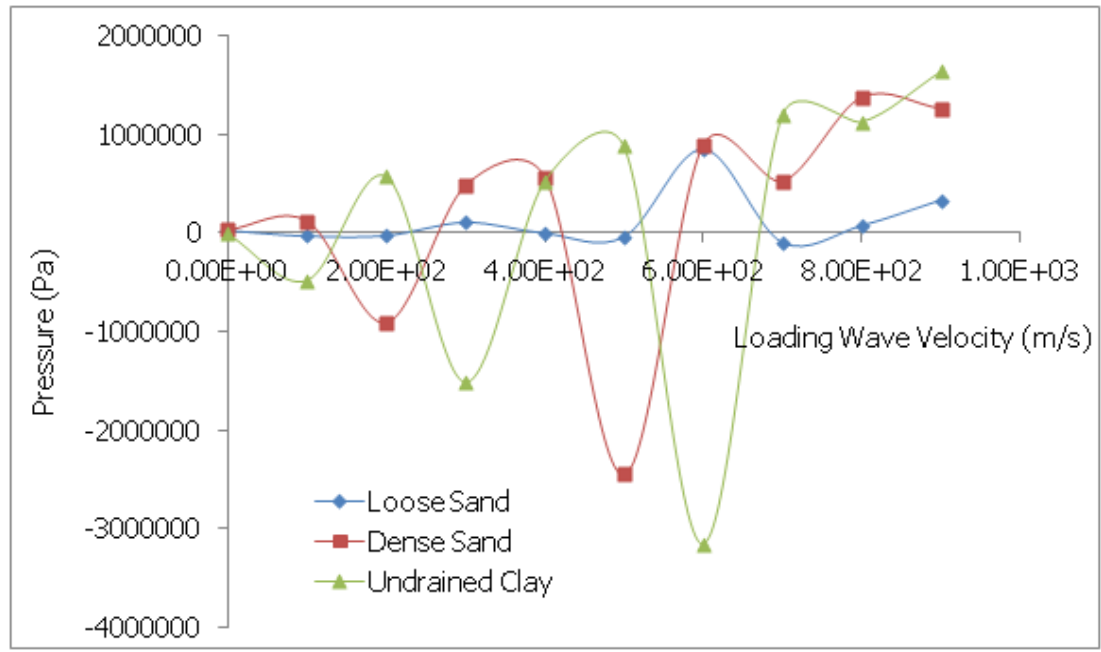

Figure 8. Pressure at the invert of underground pipes due to varying underground accidental explosions 


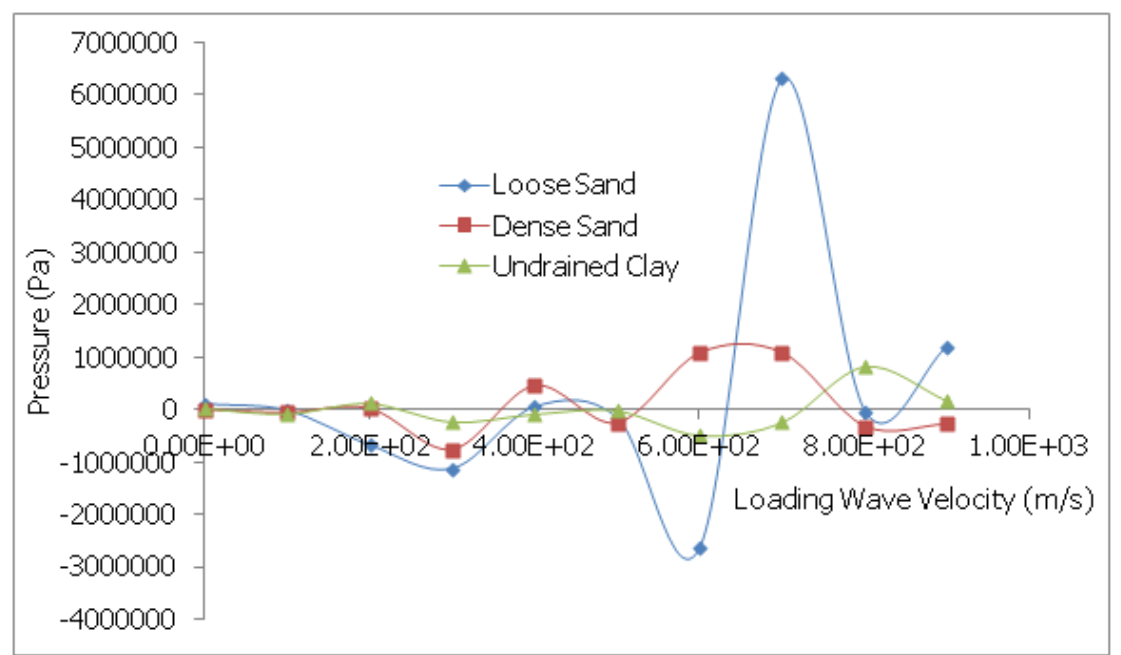

Figure 9. Pressure at the spring-line of underground pipes due to varying underground accidental explosions

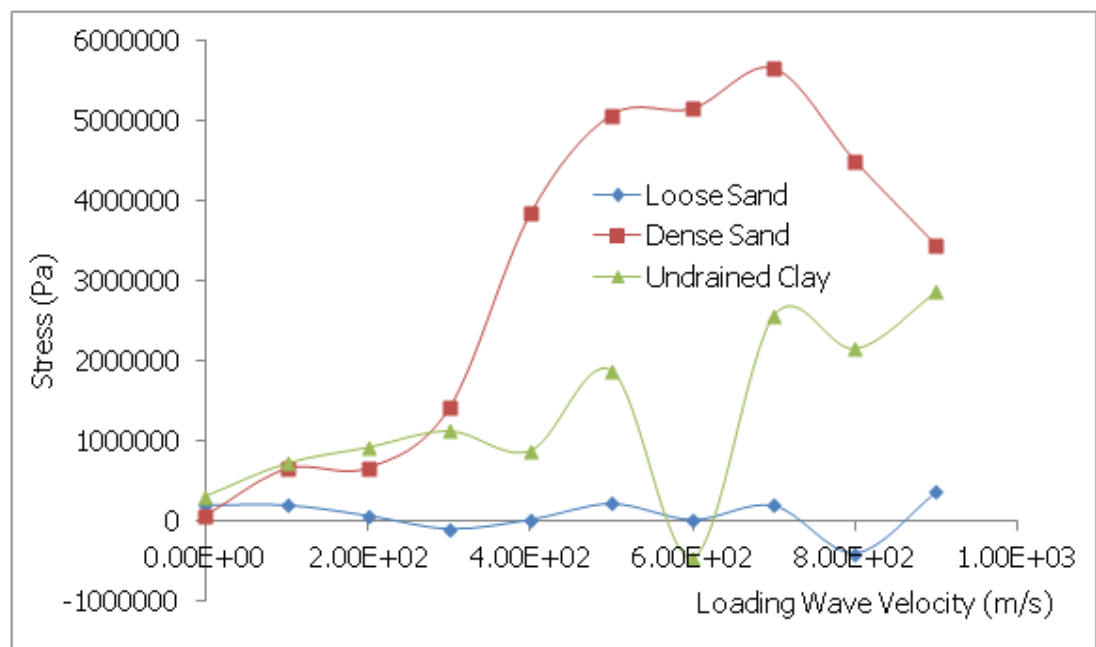

Figure 10. Stress at the crown of underground pipes due to varying underground accidental explosions

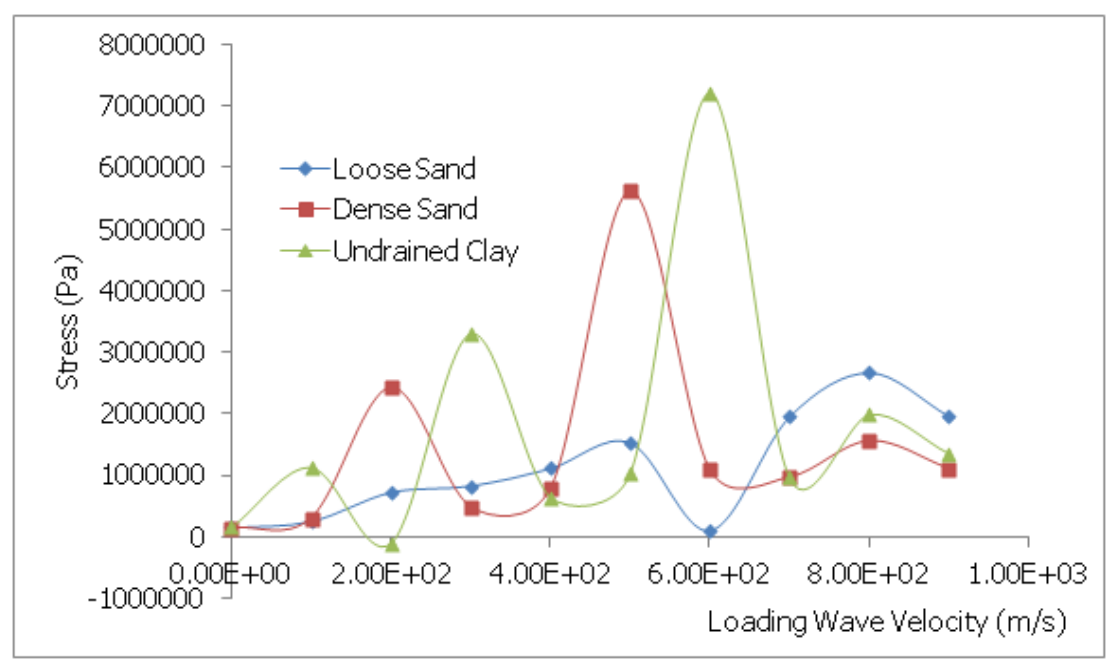

Figure 11. Stress at the invert of underground pipes due to varying underground accidental explosions 


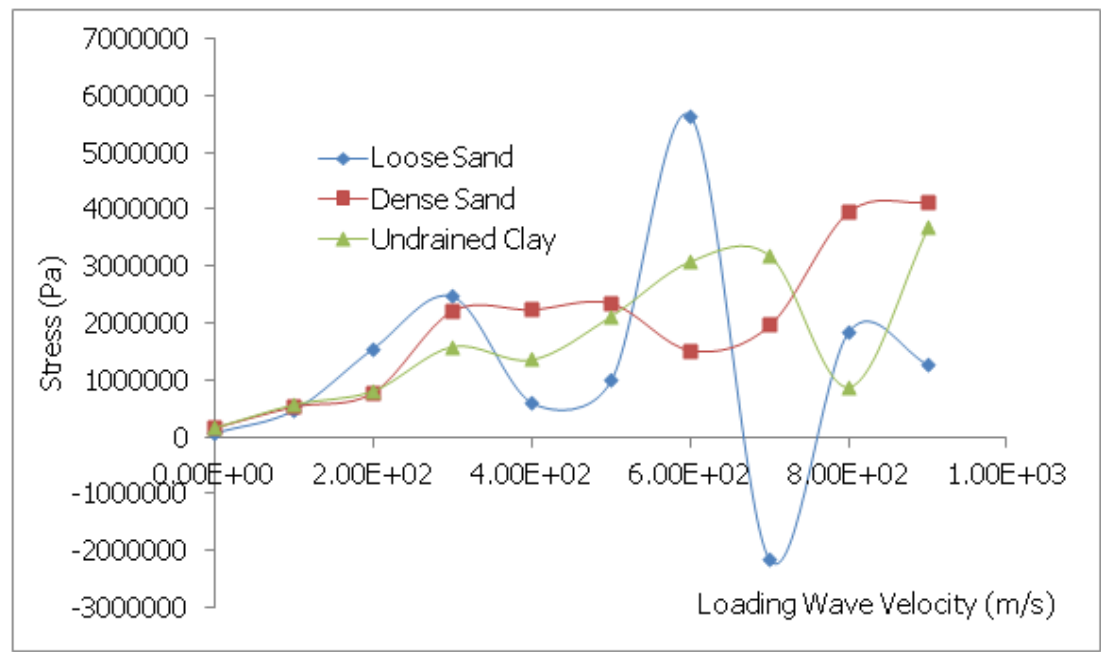

Figure 12. Stress at the spring-line of underground pipes due to varying underground accidental explosions

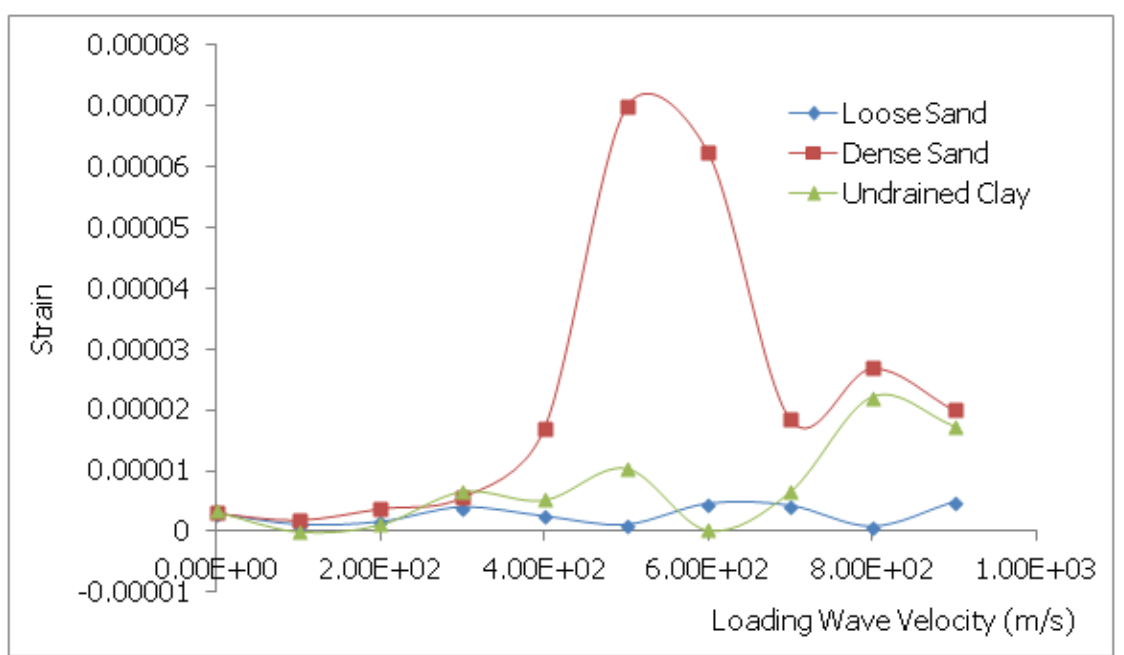

Figure 13. Strain at the crown of underground pipes due to varying underground accidental explosions

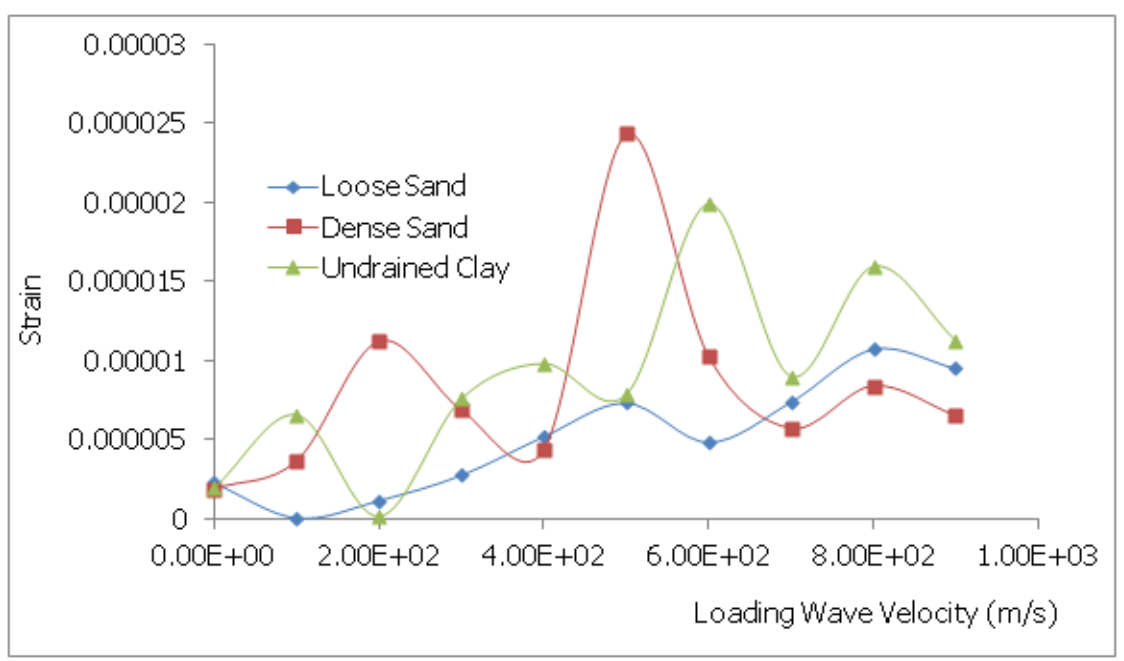

Figure 14. Strain at the invert of underground pipes due to varying underground accidental explosions 


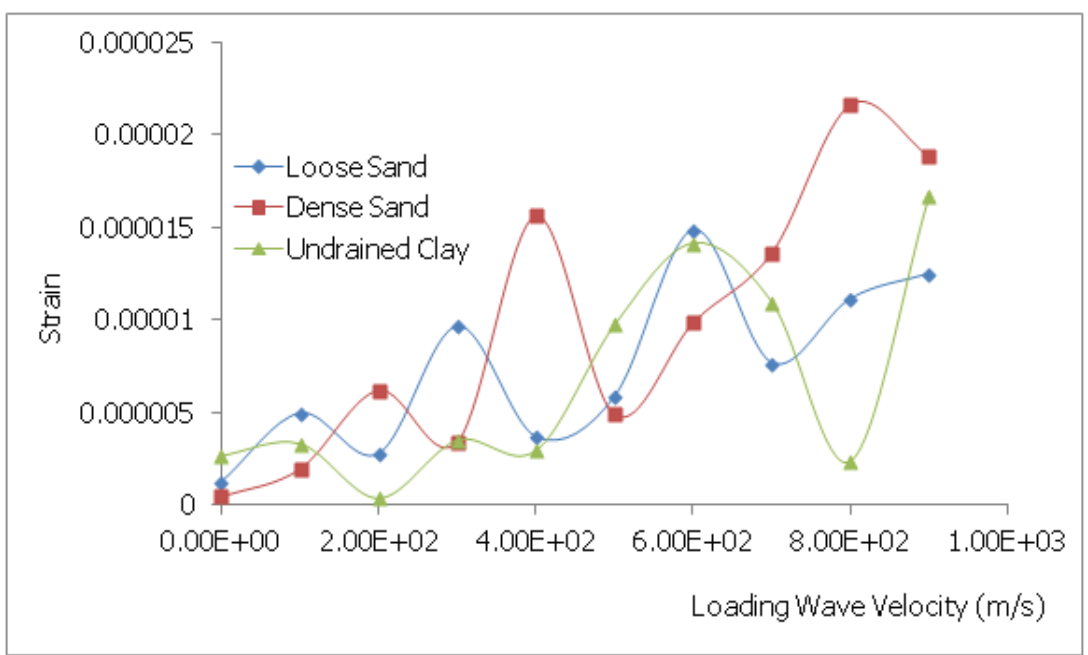

Figure 15. Strain at the spring-line of underground pipes due to varying underground accidental explosions

For the weight of explosives considered (i.e., $10 \mathrm{~kg}$ TNT to $250 \mathrm{~kg}$ TNT), loading wave velocity in sand and undrained clay reduces to seismic velocity of soil at a distance of less than $10 \mathrm{~m}$ from the point of burst of underground accidental explosions as shown in Figures 2 and 3 respectively. This is because much of the energy from the explosive yield is spent in heating, melting, fracturing and plastically deforming the soil matrix around and within the vicinity of the source of underground explosion (Olarewaju et al., 2010i). The remaining energy is released to the ground medium in the form of seismic velocity. For the loading wave velocities investigated, the maximum pressure observed at the crown, invert and spring-line of pipes buried in loose sand, dense sand and undrained clay are 1.8 Mpa $\left(\mathrm{N} / \mathrm{mm}^{2}\right), 3.3 \mathrm{Mpa}$ and $6.2 \mathrm{Mpa}$ as shown in Figures 7, 8 and 9 respectively. In addition to this, as shown in Figures 10, 11 and 12, the maximum stress at the crown, invert and spring-line of pipes buried in loose sand, dense sand and undrained clay are 5.7 Mpa, 7.2 Mpa and 5.5 Mpa respectively. Finally, the maximum strain at the crown, invert and spring-line of pipes buried in loose sand, dense sand and undrained clay are $0.00007,0.000024$ and 0.000022 as shown in Figures 13, 14 and 15 respectively.

Displacement at the crown, invert and spring-line of pipes buried in loose sand, dense sand and undrained clay increases linearly as the loading wave velocity increases as shown in Figures 4, 5 and 6 respectively. Irrespective of the ground media, displacement in the pipes is linear. In addition, as shown in Figures 7, 8 and 9, pressure changes from positive to negative in the buried pipes in all the ground media considered due to dilations and compressions caused by the transient stress pulse of compression wave from the underground accidental explosion. Furthermore, even though there is wide variation in the result due to dynamic nature of the load, as the loading wave velocities from underground accidental explosions increases, pressure shown in Figures 7, 8 and 9, stress shown in Figures 10, 11 and 12 as well as strain shown in Figures 13, 14 and 15 at the crown, invert and spring-line of pipes buried in loose sand, dense sand and undrained clay, respectively, increases. This study has shown that displacement is the most important criteria to be given priority in the design of underground pipes to resist effects of underground accidental explosions. It shows that as the displacement increases linearly due to increased loading wave velocity from underground accidental explosions, moment and stress induced in underground pipes will also increase and may eventually lead to material failure if the yield limit is exceeded.

\section{Conclusion}

In this study, the impact of varying degrees of underground accidental explosions on buried pipes has been examined. Pipes are generally laid (i. e. buried) at varying depth of burial depending on application, geotechnical properties of the ground media, etc. With time, due to hydraulic erosion, wind erosion, and other forms of erosion, the topmost part of the soil cover that forms the overburden on the underground structures like pipes is washed away. As a result of this, there is need for accidental explosion resistant evaluation of underground installations like pipes in order to have an optimal design of underground structures like pipes that would resist the effects of underground accidental explosions. This is imperative most especially around military formations where defensive and explosive weapons are stored underground, filing stations where automotive gas oil (AGO), premium motor spirit (PMS), dual purpose kerosene (DPK) are stored underground, manufacturing industrial areas where propane are stored underground, etc. 
It is important to note that due to less overburden, structural materials yield more easily at lower depth of burial due to underground accidental explosions, whereas at grater depth of burial, due to confinement, response of underground structures such as pipes is minimal (Olarewaju et al., 2010f; 2011c; 2011d). In designing underground installations like pipes to resist effects of unpredictable varying magnitude of underground accidental explosions, displacement is one of the paramount factors to be given priority compared to other observed parameters (i. e. pressure, stress and strain). This is because displacement (i. e. with respect to given distances) of underground installations like pipes results in moments and stresses that will be induced. If the moment and stress induced in underground pipes due to displacement is large and it approaches the yield stress of the material of underground installations (i.e. pipes), invariably it would result to material failure. This study has demonstrated that higher loading wave velocity would result to higher displacement which invariably would result to higher induced moment and stress if multiplied by the corresponding distances (Liang-Chaun. 1978).

\section{References}

Abaqus Inc. (2009). Abaqus Analysis User's Manuals - Documentation, Version 6.7- and 6.8-EF, D'S Simulia, Providence, Rhode Island, USA.

Abaqus Inc. (2009). Abaqus/Explicit: Advanced Topics, D'S Simulia, Providence, Rhode Island, USA.

Abaqus Inc. (2009). Geotechnical Modelling and Analysis with Abaqus, D’S Simulia, Providence, Rhode Island, USA.

AubreyJ.org. (2006). United States Department of Energy, All in Public Domain. Retrieved from http://www.doe.gov.bridge

Craig, R. F. (1994). Soil Mechanics (5th ed.). GB: Chapman and Hall Press.

Eric, T., \& Shino. (2011). Stricken Japan nuclear plant rocked by $2^{\text {nd }}$ blast. Fukushima Dai-Ichi Nuclear Plant Plagued By Cooling Issues. The Associated Press, $14^{\text {th }}$ March.

Kameswara, R. N. S. V. (1998). Vibration Analysis and Foundation ( $1^{\text {st }}$ ed.). New Delhi: Wheeler Publishing Co. Ltd.

Liang-Chaun, P. (1978). Soil-pipe interaction: Stress analysis methods for underground pipelines (pp, 67-76). AAA Technology and Specialties Co. Inc., Houston, Pipeline Industry.

Olarewaju, A. J., Kameswara Rao, N. S. V., \& Mannan, M. A. (2010a). Response of Underground Pipes due to Blast Load. Proceedings of $3^{\text {rd }}$ International Earthquake Symposium Bangladesh, Bangladesh University of Engineering Technology, Dhaka, 165-172, Mar. 5th-6th.

Olarewaju, A. J., Kameswara Rao, N. S. V., \& Mannan, M. A. (2010b). Blast Effects on Underground Pipes. Electronic Journal of Geotechnical Engineering, May, 15(F), 645-658.

Olarewaju, A. J., Kameswara Rao, N. S. V., \& Mannan, M. A. (2010c). Behaviors of Buried Pipes due to Internal Explosion. Malaysia Construction Research Journal, 9(2).

Olarewaju, A. J., Kameswara Rao, N. S. V., \& Mannan, M. A. (2010d). Blast Prediction and Characteristics for Simulating the Response of Underground Structures. Proceedings 3rd International Conference of Southeast Asian on Natural Resources and Environmental Management, Universiti Malaysia Sabah, Malaysia, Aug. $5^{\text {th }}$ $-6^{\text {th }} \cdot 384-391$.

Olarewaju, A. J., Kameswara Rao, N. S. V., \& Mannan, M. A. (2010e). Design Hints for Buried Pipes to Resist Effects of Blast. Proceedings of Indian Geotechnical Conference, Indian Institute of Technology, India, Macmillan Press, Dec. $16^{\text {th }}-18^{\text {th }}, 881-884$.

Olarewaju, A. J., Kameswara Rao, N. S. V., \& Mannan, M. A. (2010f). Guidelines for the Design of Buried Pipes to Resist Effects of Internal Explosion, Open Trench and Underground Blasts. Electronic Journal of Geotechnical Engineering, 15(J), 959-971.

Olarewaju, A. J., Kameswara Rao, N. S. V., \& Mannan, M. A. (2010g). Response of Underground Pipes due to Blast Loads by Simulation-An Overview. Electronic Journal of Geotechnical Engineering, 15(G), 831-852.

Olarewaju, A. J., Kameswara Rao, N. S. V., \& Mannan, M. A. (2010h). Response of Underground Pipes Due to Underground Blast. Proceedings of the International Agricultural Engineering Conference, China, Sept. $17^{\text {th }}-20^{\text {th }}$, pp. (I) $321-329$. 
Olarewaju, A. J., Kameswara Rao, N. S. V., \& Mannan, M. A. (2011a). Blast Effects on Underground Pipes Using Finite Element Method. Proceedings of $12^{\text {th }}$ International Conference on Quality in Research, Faculty of Engineering, University of Indonesia, Bali, Indonesia, $4^{\text {th }}-7^{\text {th }}$ July, 2511-2518.

Olarewaju, A. J., Kameswara Rao, N. S. V., \& Mannan, M. A. (2012). Chapter 20: Response of Underground Pipes to Blast Loads, Book Title: Earthquake-Resistant Structures - Design, Assessment and Rehabilitation, Abbas Moustafa (Ed.), ISBN: 978-953-51-0123-9, Geology and Geophysics, InTech Publisher, University Campus STeP Ri, Slavka Krautzeka 83/A 51000 Rijeka, Croatia, Europe, February, 507-524,

Olarewaju, A. J., Kameswara Rao, N. S. V., \& Mannan, M. A. (2011c). Simulation and Verification of Blast Load Duration for Studying the Response of Underground Horizontal and Vertical Pipes Using Finite Element Method. Electronic Journal of Geotechnical Engineering, 16(G), 785-796.

Olarewaju, A. J., Kameswara Rao, N. S. V., \& Mannan, M. A. (2011d). Dimensionless Response of Underground Pipes Due to Blast Loads Using Finite Element Method. Electronic Journal of Geotechnical Engineering, 16(E), 563-574.

Peter, D. S., \& Andrew, T. (2009). Blast Load Assessment by Simplified and Advanced Methods, Defence College of Management and Technology, Defence Academy of the United Kingdom, Cranfield University, UK.

Robert, W. D. (2002). Geotechnical Earthquake Engineering Handbook. NY: McGraw-Hill.

The Effects of Nuclear Weapons. (1977). Chapter II: Description of Nuclear Explosions - Underwater and Underground Blast. Trinity Atomic Web Site, Nuclear Weapons: History, Technology, and Consequences in History Documents, Photos, and Videos.

Unified Facilities Criteria. (2008). Structures to Resist the Effects of Accidental Explosions, UFC 3-340-02, Department of Defense, US Army Corps of Engineers, Naval Facilities Engineering Command, Air Force Civil Engineer Support Agency, USA.

United States Department of Energy. (2000). United States Nuclear Tests July 1945 through September 1992, Nevada Operations Office Las Vegas, Nevada DOE/NV--209-REV 15, 1-162. 